\title{
The Oxidase Reaction as a Taxonomic Tool
}

\author{
BY K. J. STEEL \\ National Collection of Type Cultures, London N.W. 9
}

(Received 20 December 1960)

\begin{abstract}
SUMMARY
The oxidase test of Kovacs (1956) was applied to 1660 strains of various genera, of which 210 gave a positive reaction and 64 gave a delayed positive reaction. Members of the Neisseriaceae and Pseudomonadaceae were generally oxidasepositive, whereas members of the Enterobacteriaceae and, with few exceptions, Gram-positive organisms, were oxidase-negative; equivocal results were obtained in the Brucellaceae and the genus Bacillus. Kovacs test is simple and quickly performed, but very sensitive. Some taxonomic implications of the results are discussed.
\end{abstract}

\section{INTRODUCTION}

The oxidase reaction, based upon the ability of certain bacteria to produce indophenol by the oxidation of dimethyl- $p$-phenylenediamine and $\alpha$-naphthol, was introduced by Gordon \& McLeod (1928) to aid identification of gonococci, although specificity for this organism was not claimed. A 1-1.5\% (w/v) solution of dimethyl$p$-phenylenediamine hydrochloride was poured over suspected colonies grown on a suitable medium in a Petri plate; oxidase-positive colonies developed a pink colour which successively became maroon, dark red and black in 10-30 min. The use of the more sensitive and less toxic tetramethyl compound was advocated by Ellingworth, McLeod \& Gordon (1929). Kovacs (1956) smeared bacterial growth on filter-paper impregnated with $1 \%(\mathrm{w} / \mathrm{v})$ aqueous tetramethyl-p-phenylenediamine dihydrochloride solution. Oxidase-positive organisms produced a purple coloration on the paper within 10 sec. Kovacs reported that, apart from Pseudomonas aeruginosa, the common Gram-negative rods did not produce this coloration. Gaby \& Hadley (1957) introduced their 'cytochrome oxidase' test in which a broth culture was used. The appearance of a blue colour on addition of aqueous dimethyl$p$-phenylenediamine oxalate and ethanolic $\alpha$-naphthol solutions indicated the presence of this enzyme. This test was modified by Ewing \& Johnson (1960) to permit the use of agar slope cultures. Kovacs (1956) oxidase test has now been applied to some of the organisms held in the National Collection of Type Cultures and the results are reported here.

\section{METHODS}

Organisms. A total of 1660 strains has been tested. The organisms were grown on the surface of solid media at their optimum temperature for 18-24 hr. or until distinct colonies were obtained.

Oxidase test. Growth was picked off the medium with a platinum loop and rubbed on filter-paper impregnated with $1 \%(\mathrm{w} / \mathrm{v})$ aqueous tetramethyl-p-phenylene- 
diamine dihydrochloride solution. Production of a purple colour within 10 sec. was recorded as positive, its development in 10-60 sec. as delayed positive, and the absence of coloration or its still later development as negative.

Sensitivity of test. Traces of iron catalyse the oxidation of the phenylenediamine compound with the production of a purple colour, which may give rise to false reactions, so that it is essential to use a platinum loop or wire to remove the bacterial growth for testing. The reagent loses its sensitivity and becomes discoloured on storage. A fresh batch was prepared every two weeks and kept in a glass-stoppered bottle, protected from light, in a refrigerator.

\section{RESULTS}

Of the 1660 strains tested 210 gave positive and 64 gave delayed reactions (Table 1 ).

Table 2 gives details of genera in which prompt positive results were obtained. Delayed positive reactions were common in the genera Bacillus, Brucella, Haemophilus, and Pasteurella.

\section{Table 1. Distribution of oxidase activity among bacterial genera}

Total number of strains tested was 1660 ; of these 210 were positive, 64 were delayed positive and 1386 were negative.

\begin{tabular}{|c|c|c|c|c|c|c|c|c|c|}
\hline Genus & $\begin{array}{l}\text { No. of } \\
\text { strains } \\
\text { tested }\end{array}$ & + & $(+)$ & - & Genus & $\begin{array}{r}\text { No. of } \\
\text { strains } \\
\text { tested }\end{array}$ & + & $(+)$ & - \\
\hline Achromobacter & 18 & 2 & 4 & 12 & Neisseria & 57 & 57 & . & - \\
\hline Actinobacillus & 7 & . & 3 & 4 & Nocardia & $\boldsymbol{9}$ & . & . & 9 \\
\hline Actinomyces & 13 & . & . & 13 & Pasteurella & 62 & 15 & 10 & 37 \\
\hline Aerococcus & 6 & . & - & 6 & Proteus & 40 & . & - & 40 \\
\hline Aeromonas & 5 & 5 & . & . & Pseudomonas & 33 & 32 & $\mathbf{1}$ & . \\
\hline Alcaligenes & 7 & 7 & . & . & Salmonella & 97 & . & . & 97 \\
\hline Arizona & 80 & . & . & 80 & Serratia & 12 & . & . & 12 \\
\hline Bacillus & 84 & 2 & 21 & 61 & Shigella & 89 & . & . & 89 \\
\hline Bordetella & 23 & 19 & 1 & $\mathbf{3}$ & Staphylococcus & 97 & . & $\mathbf{1}$ & 96 \\
\hline Brucella & $\mathbf{3 1}$ & 14 & 6 & 11 & Streptocococcus & 130 & . & • & 130 \\
\hline Chromobacterium & 6 & - & . & $6 *$ & Streptomyces & 6 & . & . & 6 \\
\hline Citrobacter & 17 & . & - & 17 & Vibrio & 35 & 32 & . & $\mathbf{3}$ \\
\hline Clostridium & 54 & . & . & $\mathbf{5 4}$ & & & & & \\
\hline Corynebacterium & 91 & - & . & 91 & Miscellaneous bacteria & & & & \\
\hline Enterobacter $\dagger$ & 17 & . & - & 17 & Bacteroides necrophorus & $\mathbf{1}$ & . & - & 1 \\
\hline Erysipelothrix & 7 & . & . & 7 & Coccobacillus mycetoides & 1 & . & . & 1 \\
\hline Escherichia & 107 & . & . & 107 & Flavobacterium meningosepticum & $\mathbf{1}$ & $\mathbf{1}$ & . & . \\
\hline Haemophilus & 33 & 5 & 13 & 15 & Jensenia canicruria & 1 & . & • & 1 \\
\hline Hafnia & 11 & . & . & 11 & Kurthia zopfii & 2 & . & . & 2 \\
\hline Klebsiella & 274 & . & - & 274 & Leptotrichium dentium & 1 & . & . & $\mathbf{1}$ \\
\hline Lactobacillus & 7 & . & . & 7 & Noguchia granulosis & 1 & . & . & 1 \\
\hline Leuconostoc & 3 & . & . & $\mathbf{3}$ & Pediococcus cerevisiae & $\mathbf{1}$ & . & . & $\mathbf{1}$ \\
\hline Listeria & 9 & . & . & 9 & Polysepta pedis & $\mathbf{1}$ & . & . & $\mathbf{1}$ \\
\hline Loefflerella & 15 & 8 & $\mathbf{3}$ & 4 & 'Pseudomonas iodinum' & 1 & . & $\mathbf{1}$ & . \\
\hline Lophomonas & 4 & 4 & . & . & Sarcina sp. & $\mathbf{1}$ & . & . & $\mathbf{1}$ \\
\hline Moraxella & 10 & 7 & . & $\dot{3}$ & Spirillum rubrum & $\mathbf{1}$ & • & . & $\mathbf{1}$ \\
\hline Mycobacterium & 40 & . & . & 40 & Streptobacillus moniliformis & $\mathbf{1}$ & . & . & 1 \\
\hline
\end{tabular}




\section{Oxidase, catalase and aerobiosis}

From the results in Tables 1 and 2 it is seen that the oxidase-positive strains were all aerobes or facultative anaerobes, with the exception of Vibrio fetus which is micro-aerophilic. Gordon \& McLeod (1928) believed the oxidase reaction to be restricted to organisms which grew best in the presence of oxygen and which formed catalase. In a study of organisms resembling Alcaligenes faecalis, Moore \& Pickett (1960) found 9 oxidase-positive strains which were catalase-negative, but of the organisms studied here all oxidase-positive strains produced catalase. None of the strict anaerobes showed any oxidase activity. Its absence from these organisms and from the Lactobacillaceae is in agreement with the lack of cytochrome in these organisms (Deibel \& Evans, 1960).

Table 2. Species within the oxidase-positive genera of bacteria

\begin{tabular}{|c|c|c|c|c|c|c|c|c|c|}
\hline Species & $\begin{array}{c}\text { No. } \\
\text { of } \\
\text { strains }\end{array}$ & + & $(+)$ & - & Species & $\begin{array}{c}\text { No. } \\
\text { of } \\
\text { strains }\end{array}$ & + & $(+)$ & - \\
\hline Achromobacter anitratus & 11 & - & . & 11 & Moraxella liquefaciens & 1 & 1 & - & \\
\hline A. equuli & 7 & 2 & 4 & 1 & M. lwoffii & $\mathbf{3}$ & - & . & $\mathbf{3}$ \\
\hline Aeromonas hydrophila & $\mathbf{3}$ & 3 & - & . & Neisseria animalis & $\mathbf{1}$ & 1 & . & . \\
\hline A. liquefaciens & 1 & 1 & - & . & N. catarrhalis & 7 & 7 & - & - \\
\hline A. salmonicida & 1 & 1 & - & . & N. flavescens & 3 & $\mathbf{3}$ & . & - \\
\hline Alcaligenes denitrificans & 1 & 1 & . & - & N. gonorrhoeae & 12 & 12 & - & . \\
\hline A. faecalis & $\mathbf{5}$ & $\mathbf{5}$ & . & . & N. meningitidis & 32 & 32 & . & . \\
\hline A. viscosus & 1 & 1 & - & . & N. pharyngis & $\mathbf{2}$ & 2 & . & • \\
\hline Bordetella bronchiseptica & 12 & 12 & . & . & Pasteurella haemolytica & 6 & 6 & . & . \\
\hline B. parapertussis & $\mathbf{3}$ & . & - & $\mathbf{3}$ & $P \cdot$ pestis & 10 & . & . & 10 \\
\hline B. pertussis & 8 & 7 & 1 & - & P. pseudotuberculosis & 20 & . & . & 20 \\
\hline Brucella abortus & 12 & 8 & 3 & 1 & P. septica & 26 & 9 & 10 & 7 \\
\hline B. melitensis & 6 & $\mathbf{3}$ & 2 & 1 & Pseudomonas aeruginosa & 14 & 14 & . & - \\
\hline B. neotomae & 4 & - & - & 4 & P. chlororaphis & $\mathbf{1}$ & 1 & . & - \\
\hline B. ovis & 1 & : & - & 1 & P. diminuta & 1 & 1 & - & $\cdot$ \\
\hline B. paramelitensis & $\mathbf{1}$ & $\mathbf{1}$ & - & . & P. fluorescens & $\mathbf{5}$ & 5 & - & . \\
\hline B. suis & 7 & 2 & 1 & 4 & P. graveolens & 1 & 1 & . & - \\
\hline Haemophilus aegyptius & 3 & - & $\mathbf{2}$ & $\mathbf{1}$ & P. mucidolens & 1 & 1 & . & . \\
\hline H. aphrophilus & 4 & - & - & 4 & P. ovalis & 2 & 1 & $\mathbf{1}$ & • \\
\hline H. canis & 2 & - & 1 & 1 & P. polycolor & 1 & 1 & - & - \\
\hline H. gallinarum & 1 & - & . & 1 & P. syncyanea & 1 & 1 & . & . \\
\hline H. haemolyticus & 1 & - & 1 & $\therefore$ & Pseudomonas spp. & 6 & 6 & - & - \\
\hline H. influenzae & 16 & 4 & 7 & $\mathbf{5}$ & Vibrio choleraeasiaticae & 15 & 15 & - & - \\
\hline H. parainfluenzae & 2 & - & - & 2 & V. el Tor & 10 & 10 & - & - \\
\hline H. suis & 4 & 1 & $\mathbf{2}$ & 1 & $V \cdot$ fetus & 1 & $\mathbf{1}$ & - & . \\
\hline Loefflerella mallei & 5 & - & 1 & 4 & V. metchnikovii & 1 & . & - & 1 \\
\hline L. pseudomallei & 10 & 8 & 2 & $\cdot$ & $V \cdot$ paracholerae & 1 & 1 & - & - \\
\hline Lophomonas alcaligenes & 4 & 4 & - & . & $V \cdot$ percolans & 1 & $\mathbf{1}$ & . & . \\
\hline Moraxella bovis & 3 & 3 & - & $\cdot$ & $V$. proteus & 2 & - & . & 2 \\
\hline M. lacunata & $\mathbf{3}$ & $\mathbf{3}$ & . & • & Vibrio spp. & 4 & 4 & . & . \\
\hline
\end{tabular}

$+=$ positive reaction $;(+)=$ delayed positive reaction; $-=$ negative reaction.

\section{Gram-positive organisms}

With the exception of 'Pseudomonas iodinum', one strain of Staphylococcus lactis, and some Bacillus spp., oxidase activity was not found among Gram-positive organisms.

Oxidase activity in Bacillus anthracis and $B$. subtilis was recorded by Gordon \& McLeod (1928) and Price (1929). With Kovacs technique, few prompt positives but 
several delayed reactions were obtained among strains of the 22 species of the genus Bacillus tested here.

One strain of Bacillus laterosporus gave a positive reaction, one a delayed positive and one a negative reaction; with 7 strains of $B$. licheniformis, 1 positive, 2 delayed positive and 4 negative reactions were obtained. Delayed positive reactions were obtained with 5 strains of $B$. sphaericus, 2 of $B$. alvei and one each of $B$. freundenreichii and $B$. lentus. Some strains of the following species gave delayed positive reactions: $B$. anthracis (2 of 4 strains tested), B. brevis (1 of 3 ), B. cereus (1 of 7 ), $B$. mycoides (1 of 3), B. subtilis (4 of 14).

Oxidase activity was not observed in the following species: Bacillus alcalophilus (1 strain), B. carotarum (1), B. circulans (4), B. coagulans (3), B. loehnisii (1), B. macerans (4), B. megaterium (6), B. pantothenticus (4), B. polymyxa (2), B. pumilis (7) and $B$. stearothermophilus (1).

\section{Gram-negative organisms}

Oxidase activity was more common among the Gram-negative organisms. All strains tested of the genus Pseudomonas were oxidase-positive, as found by Buttiaux \& Gagnon (1958); however, in one strain of $P$. ovalis the reaction was delayed. The observation of Gould \& McLeod (1960) that young unpigmented growth of $\boldsymbol{P}$. aeruginosa gave a more intense oxidase reaction than older colonies was confirmed, Köhler (1959) reported $\boldsymbol{P}$. fluorescens to be oxidase-negative but, like Klinge (1960), I could not confirm this.

Only 5 strains of Aeromonas were tested, but all were oxidase-positive, a result confirming Ewing \& Johnson (1960) who tested 36 strains. All strains of Achromobacter anitratus were oxidase-negative but 7 strains of $A$. equuli (Actinobacillus equuli) gave equivocal results. Buttiaux \& Gagnon (1958) found fewer oxidasepositive strains of Aeromonas (5 of 24), but 12 of 23 strains of Achromobacter and none of $\boldsymbol{\gamma}$ strains of ' $\boldsymbol{B}$. anitratum' were positive.

Strains of the genus Alcaligenes all gave positive reactions, although the colour produced on the reagent-impregnated paper intensified greatly after contact for 10 sec. Ewing \& Johnson (1960) found the genus to be oxidase-positive but they too examined only a few strains. Gaby \& Free (1958) considered Kovacs test to be over-sensitive because strains of $\boldsymbol{A}$. faecalis gave reactions similar to those of Pseudomonas aeruginosa.

With the exception of Vibrio metchnikovii and $V$. proteus, all strains tested of the genus Vibrio were oxidase-positive. Oxidase activity was found by Ewing \& Johnson (1960) in all of 115 strains of $V$. choleraeasiaticae and in 12 other strains of the genus. The four strains of Lophomonas alcaligenes were oxidase-positive, a character of the species (Galarneault \& Leifson, 1956). In the genus Neisseria, all strains tested gave a positive reaction.

Because of their violet pigment, which was absorbed into the filter paper, difficulty was encountered in determining the oxidase activity of Chromobacterium species. Tests made with non-pigmented colonies and young cultures before the pigment was well developed failed to show definite oxidase activity. In Table 1 these strains have therefore been recorded as oxidase-negative, although it may be possible to observe oxidase activity by other test methods. The one strain of Flavobacterium meningosepticum gave a positive oxidase reaction, as originally 
reported by King (1959). Reports of oxidase activity in this genus and in Xanthomonas are conflicting (Buttiaux \& Gagnon, 1958; Ewing \& Johnson, 1960), mainly because of the small number of strains tested.

Of the total of 1660 strains tested in the present work, 744 were members of the Enterobacteriaceae and none of these gave a positive or even a delayed positive reaction. Oxidase activity was not demonstrated in 800 strains of this family by Buttiaux \& Gagnon (1958) nor in 1222 strains tested by Ewing \& Johnson (1960). Gordon \& McLeod (1928) reported Serratia marcescens to be oxidase-positive, but no confirmation of this has been obtained.

The Brucellaceae ('Parvobacteriaceae') was the family most heterogeneous in oxidase activity. Two strains of Actinobacillus actinomycetemcomitans and one strain each of Bacteroides necrophorus, Noguchia granulosis and Streptobacillus moniliformis were oxidase-negative. Of 5 strains of $A$. lignieresi, 3 gave a delayed positive reaction when colonies from blood agar plates were tested, but very weak or negative results when serum glucose agar was used.

All strains of Bordetella bronchiseptica and $\boldsymbol{B}$. pertussis were oxidase-positive (although in one strain of the latter the reaction was delayed $15 \mathrm{sec}$.) whereas those of B. parapertussis were negative. Gordon \& McLeod (1928) found that stock strains of $\boldsymbol{B}$. pertussis on Dorset egg medium gave a positive reaction but that fresh isolates were negative. They noted that uninoculated Bordet-Gengou medium gave a positive reaction on addition of the test reagent. Using the tetramethyl compound (Ellingworth et al. 1929), B. pertussis was found to be oxidase-positive. Lacey (1960) reported that both $B$. bronchiseptica and $B$. pertussis gave positive oxidase reactions within 30 sec. when a loopful of the reagent was applied to the bacterial growth. Lautrop (1960) considered these two species to be oxidase-positive within $15 \mathrm{sec}$. by Kovacs method; he also noted the possibility of false positives due to the high proportion of blood in many media for $B$. pertussis. For the tests reported here, this organism was grown on Bordet-Gengou medium, except for two phase IV strains which were grown on Lemco agar.

The older species of Brucella gave equivocal results whereas strains of two proposed new species, $B$. neotomae and $B$. ovis, did not show oxidase activity. It was not possible to distinguish American and Danish strains of $B$. suis on their oxidase activity. B. melitensis was reported by Gordon \& McLeod (1928) to be oxidasepositive. In a quantitative study Richardson (1957) showed that species of this genus differed markedly in their cytochrome oxidase activity; typical strains of $\boldsymbol{B}$. abortus had twice the activity of $B$. melitensis and more than twice that of $B$. suis or thionin-resistant strains of $B$. abortus. Strong peroxidase activity was reported (Krčméry, 1959) in B. suis, and Smith (1954) noted that $p$-phenylenediamines might be oxidized by peroxidases. It is thus possible that an 'oxidase' activity in $B$. suis may be a reflexion of this side reaction rather than of oxidase proper.

Equivocal results were also obtained in the genus Haemophilus; over half the strains tested showed some oxidase activity. With dimethyl- $p$-phenylenediamine, $H$. influenzae was originally reported to be oxidase-negative, but use of the more sensitive tetramethyl compound showed it to be positive (Ellingworth et al. 1929). With the exception of $\boldsymbol{H}$. influenzae, few strains of the other species of this genus were tested in the present work. The 4 strains of $H$. aphrophilus, which were grown in an atmosphere of $\mathrm{CO}_{2}$, were all oxidase-negative. 
Strains of Loefflerella pseudomallei were all oxidase-positive, although in two strains the reaction was delayed ( $15 \mathrm{sec}$.), whereas 4 strains of $L$. mallei gave a negative and 1 strain a delayed (30 sec.) positive reaction. Gordon \& McLeod (1928) reported L. mallei as oxidase-positive and Fournier (1959) reported $L$. pseudomallei to be slowly positive by Gaby \& Hadley's method. Miller et al. (1948) reported both species to be oxidase-positive. With the exception of Moraxella lwoffi, all members of the genus Moraxella were oxidase-positive, this is in agreement with the results of Henriksen (1952).

Strains of Pasteurella pseudotuberculosis and $\boldsymbol{P}$. pestis were devoid of oxidase activity. $\boldsymbol{P}$. pestis has been reported as weakly oxidase-positive (Gordon \& McLeod, 1928). Strains of $\boldsymbol{P}$. haemolytica gave positive reactions whereas variable results were obtained with $\boldsymbol{P}$. septica.

\section{DISCUSSION}

The oxidase reaction was originally thought to depend on the presence of both peroxide and peroxidase (Gordon \& McLeod, 1928). It is now believed to be due to the presence of a cytochrome oxidase, the enzyme which catalyses the oxidation of reduced cytochrome by molecular oxygen and which acts as the terminal stage in electron transfer. Most aerobic and facultatively anaerobic bacteria contain a cytochrome system which acts as an electron carrier in aerobic respiration. Many of these organisms also produce catalase. The cytochromes are a group of respiratory pigments comprising a number of related iron-porphyrin compounds. The distribution of these cytochromes varies with different bacteria; some have several while others have only one or none at all. Most workers have used the visual spectroscope to examine the absorption spectra of bacterial cytochromes, a technique which is not sufficiently sensitive to distinguish between cytochromes whose absorption maxima are close together. Smith (1954), in a review of bacterial cytochromes, pointed out the disagreement among various workers about the distribution of the cytochromes. Castor \& Chance (1959) demonstrated the existence of four different cytochrome oxidases in various bacteria.

Many of the oxidase-positive organisms (Tables 1 and 2) have been reported in the past to contain cytochrome $c$, a component which is not autoxidizable but only oxidized in the presence of cytochrome $c$ oxidase. The distribution, identity and nomenclature of the various cytochrome components remain confused, however. Consequently in this paper the term 'oxidase' is used without prejudice and no assumptions have been made about the possible identity of the material responsible for positive oxidase reactions with cytochrome $c$ oxidase or any other component of the bacterial cell.

For a test to be of taxonomic value it is imperative that the results be reproducible with a standard technique. The oxidase test used at present differs in different laboratories both in the method and the reagents used. Gaby \& Free (1958) claimed that the cytochrome oxidase test (Gaby \& Hadley, 1957) was more accurate than Kovacs method, which they considered to be over-sensitive. Buttiaux \& Gagnon (1958) found Gaby \& Hadley's reaction to be suitable with Pseudomonas strains but not with other organisms which produced a slow coloration, making it difficult to decide whether it was a slow oxidase reaction or autoxidation of the reagent. Kovacs method, on the other hand, was rapid, simple and sensitive. Köhler (1959) 
found a margin of error of up to $12 \%$ in Gaby \& Hadley's test and the observation time had to be increased to $20 \mathrm{~min}$. Klinge is reported to have stated (Billing, 1960) that the number of strains of $\boldsymbol{P}$. aeruginosa giving a positive reaction depended on the medium on which they were grown. Kovacs method, besides being simpler and quicker than the other methods, has the advantage that only a portion of a colony is needed for the test. It is undoubtedly a more sensitive method of determining oxidase activity than the other tests. The reagents used in the various methods include $p$-phenylenediamine hydrochloride, dimethyl-p-phenylenediamine (also known as $p$-aminodimethylaniline) hydrochloride or oxalate (Carpenter, Suhrland \& Morrison, 1947) and tetramethyl-p-phenylenediamine dihydrochloride, all with or without the addition of aniline or $\alpha$-naphthol. The instability of solutions of the $p$-phenylenediamines is a disadvantage common to all test methods.

\section{Taxonomic implications}

Although in many genera only a few strains have been examined, the taxonomic implications of the results need appraisal. The genus Aeromonas has many of the characters of the Enterobacteriaceae; it differs in being oxidase-positive and polarly flagellate. It has been suggested (Stevenson, 1959) that all members of the genus Aeromonas are unpigmented members of the genus Serratia. Oxidase activity has not been found in strains of Serratia and there is no evidence that the pigment prodigiosin plays any role in respiration in a manner analogous to that of 'oxidase'; Stevenson's hypothesis is therefore not supported.

The genus Alcaligenes is not yet satisfactorily delineated and the literature abounds with contradictory statements about its oxidase activity. Türck (1952) found that her strains formed two groups, oxidase-positive vibrio-like forms and oxidase-negative non-motile rods. Buttiaux \& Gagnon (1958) considered that Alcaligenes should be included in Achromobacter, as they could not find Alcaligenes faecalis to be motile. Klinge (1958) thought that 'Bacterium anitratum', B 5 W organism, 'Diplococcus mucosus' and similar organisms should be classified as Alcaligenes. He rejected pleomorphism as a criterion for classification but stressed the importance of a negative oxidase reaction. Moore \& Pickett (1960) questioned the validity of the genus Alcaligenes because they found few isolates of $\boldsymbol{A}$. faecalis which resembled the original description in having peritrichous flagella. Of their 40 strains, 20 were oxidase-positive and 2 weakly positive and they consider they should be included in the genus Achromobacter. Haupt (1957) listed Achromobacter equuli, which gave equivocal results in my tests, as Actinobacillus equuli. Accepting this, it may be suggested that it would be expedient for oxidase-positive organisms now in the genera Achromobacter or Alcaligenes to be classified as Alcaligenes and oxidase-negative organisms as Achromobacter. A strain of Alcaligenes faecalis (NCTC 415) designated as 'type' by Winslow, Kligler \& Rothberg (1919) is oxidasepositive as is the type strain of $\boldsymbol{A}$. denitrificans.

The absence of oxidase activity in Moraxella lwoffii distinguishes it from the other recognized species of Moraxella. Henriksen (1952) discussed the taxonomy of this genus and considered that it might be closely related to Neisseria, in a relation analogous to that between lactobacilli and streptococci. In a later paper (1960) he stated that $M$. lwoffi did not belong to the genus Moraxella. Klinge (1958) would 
include $M$. lwoffii in the genus Alcaligenes, but from my results it would seem better to place it in the genus Achromobacter.

Brindle \& Cowan (1951) demonstrated that the type of flagellation of Loefflerella pseudomallei warranted its inclusion in the Pseudomonadaceae; they concluded, however, that it was closely related to $L$. mallei and the two species should form a genus which should not be combined with any then accepted genus of the Pseudomonadaceae. Wetmore \& Gochenour (1956) agreed that $L$. pseudomallei could be included in this family. Fournier (1959), however, considered that there was no phylogenetic relation between this organism and Pseudomonas aeruginosa, and that L. pseudomallei and L. mallei were species of the same genus. Bergey's Manual (1957) listed these two organisms in different genera, as Pseudomonas pseudomallei and Actinobacillus mallei. The demonstration of oxidase activity in the former and its virtual absence from the latter is additional evidence for the inclusion of $L$. pseudomallei in the Pseudomonadaceae and the exclusion of $L$. mallei from this family.

'Pseudomonas iodinum' is a non-motile, non-sporing Gram-positive rod. Sneath (1960) did not consider that it should be included in the genus Pseudomonas as it has the morphology of a diphtheroid; he thought that it may belong to the genus Corynebacterium or Brevibacterium. Its oxidase activity excludes it from the first genus, however, if absence of oxidase activity is a character of the genus as a whole. (Only members of this genus which are of medical or veterinary interest were examined.) Reports have not been found in the literature about oxidase determinations in species of Corynebacterium from plant sources or in species of Brevibacterium. For the present it is felt that this organism should be retained in the genus $\boldsymbol{P}$ seudomonas until an 'oxidase spectrum' has been determined.

In addition to the organism tested here, the oxidase activity of some other genera has been reported. Ewing \& Johnson (1960) found only 3 slow and weak positives among 34 strains of Erwinia tested. Oxidase activity has been demonstrated in some strains of Veillonella (Berger, 1960), and in some leptospires (Goldberg \& Armstrong, 1959; Faine, 1960) although Czekalowski, McLeod \& Rodican (1953) obtained equivocal results with these organisms.

The results reported here confirm the claims made by various workers that the oxidase test is of value in distinguishing between different groups of organisms. Previously attention has been directed to the Enterobacteriaceae and the Pseudomonadaceae, but evidence is now accumulating that the test can be of value in other groups. Of the methods for carrying out the test that of Kovacs is reliable so long as freshly prepared reagent is used and a time limit for positives is set which is in accordance with the degree of sensitivity required.

\section{REFERENCES}

Berger, U. (1960). Oxydationsfermente bei Veillonella alcalescens. Z. Hyg. InfektKr. 146, 440.

Bergey's Manual of Determinative Bacteriology. (1957). 7th ed. Ed. R. S. Breed, E. G. D. Murray \& N. R. Smith. London: Baillière, Tindall and Cox.

Billing, E. (1960). The bacterial genera Pseudomonas and Achromobacter. Nature, Lond., $188,25$.

Brindle, C. S. \& Cowan, S. T. (1951). Flagellation and taxonomy of Whitmore's bacillus. J. Path. Bact. 63, 571. 
Buttiaux, R. \& Gagnon, P. (1958). Au sujet de la classification des Pseudomonas et des Achromobacter. Ann. Inst. Pasteur Lille, 10, 121.

Carpenter, C. M., Suhrland, L. G. \& Morrison, M. (1947). The oxalate salt of $p$-aminodimethylaniline, an improved reagent for the oxidase test. Science, 105, 649.

Castor, L. N. \& Chance, B. (1959). Photochemical determinations of the oxidases of bacteria. J. biol. Chem. 234, 1587.

Czekalowski, J. W., McLeod, J. W. \& Rodican, J. (1953). The growth and respiration of leptospira in solid or semi-solid media with special reference to Dinger's phenomenon. Brit. J. exp. Path. 34, 588.

Deibel, R. H. \& Evans, J. B. (1960). Modified benzidine test for the detection of cytochrome-containing respiratory systems in micro-organisms. J. Bact. 79, 356.

Ellingworth, S., McLeod, J. W. \& Gordon, J. (1929). Further observations on the oxidation by bacteria of compounds of the para-phenylene diamine series. J. Path. Bact. 32, 173.

Ewing, W. H. \& Johnson, J. G. (1960). The differentiation of Aeromonas and C27 cultures from Enterobacteriaceae. Int. Bull. bact. Nom. Tax. 10, 223.

FaINe, S. (1960). Catalase activity in pathogenic leptospira. J. gen. Microbiol. 22, 1.

Fournier, J. (1959). Rapport Annuel sur le Fonctionnement Technique de l'Institut Pasteur du Viêt-Nam, année, 1958. Saigon: Kim-Lai An-quan.

Gaby, W. L. \& Free, E. (1958). Differential diagnosis of Pseudomonas-like microorganisms in the clinical laboratory. J. Bact. 76, 442.

Gaby, W. L. \& Hadley, C. (1957). Practical laboratory test for the identification of Pseudomonas aeruginosa. J. Bact. 74, 356.

Galarneault, T. P. \& Leifson, E. (1956). Taxonomy of Lophomonas n.gen. Canad. J. Microbiol. 2, 102.

Goldberg, H. S. \& Armstrong, J. C. (1959). Oxidase reaction with leptospiral colonies and its adaptation to antibiotic sensitivity testing. $J$. Bact. 77, 512.

Gordon, J. \& MCLeod, J. W. (1928). The practical application of the direct oxidase reaction in bacteriology. J. Path. Bact. 31, 185.

Gould, J. C. \& McLEOD, J. W. (1960). A study of the use of agglutinating sera and phage lysis in the classification of strains of Pseudomonas aeruginosa. J. Path. Bact. 79, 295.

Haupt, H. (1957). In Bergey's Manual of Determinative Bacteriology (1957), p. 415. 7th ed. Ed. R. S. Breed, E. G. D. Murray \& N. R. Smith. London: Baillière, Tindall and Cox.

Henriksen, S. D. (1952). Moraxella: classification and taxonomy. J. gen. Microbiol. 6, 318.

Henriksen, S. D. (1960). Moraxella. Some problems of taxonomy and nomenclature. Int. Bull. bact. Nom. Tax. 10, 23.

Hormaeche, E. \& Edwards, P. R. (1960). A proposed genus Enterobacter. Int. Bull. bact. Nom. Tax. 10, 71 .

KING, E. O. (1959). Studies on a group of previously unclassified bacteria associated with meningitis in infants. Amer. J. clin. Path. 31, 241.

KLINGE, K. (1958). Zur Systematik gramnegativer, pleomorpher Kohlehydrate nichtspaltender und Oxydase-negativer Diplobakterien. Arch. Hyg., Berl. 142, 171.

KuINGe, K. (1960). Die Bedeutung der Oxydase-Reaktion für die Identifizierung von Pseudomonas aeruginosa, Pseudomonas fluorescens und Pseudomonas putida. Arch. Hyg., Berl., 144, 263.

KöHLer, W. (1959). Differentialdiagnose von Pseudomonas aeruginosa durch Cytochromoxydase Nachweis (Gaby Test). Z Zbl. Bakt. (Abt. 1), 176, 476.

Kovacs, N. (1956). Identification of Pseudomonas pyocyanea by the oxidase reaction. Nature, Lond., 178, 703.

KRČMÉry, V. (1959). A rapid biochemical method for the differentiation of Brucella suis. Peroxidase activity of Brucella. J. Hyg. Epidem. Microbiol. Immunol. (Prague), 3, 314.

LACEY, B. W. (1960). Cultural diagnosis of whooping cough. Bull. World Hlth Org. 23, 31.

LAUTrop, H. (1960). Laboratory diagnosis of whooping cough or Bordetella infections. Bull. World Hith Org. 23, 15. 
Miller, W. R., Pannelu, L., Cravitz, L., Tanner, W. A. \& Ingalus, M. S. (1948). Studies on certain biological characteristics of Malleomyces mallei and Malleomyces pseudomallei. I. Morphology, cultivation, viability and isolation from contaminated specimens. J. Bact. 55, 115.

Moore, H. B. \& Picketт, M. J. (1960). Organisms resembling Alcaligenes faecalis. Canad. J. Microbiol. 6, 43.

Price, I. N. O. (1929). The oxidase reaction in the laboratory diagnosis of gonorrhoea. Brit. med. J. i, 199.

Richardson, M. (1957). Cytochrome oxidase in cells of the genus Brucella. J. Bact. 74, 699.

SмiтH, L. (1954). Bacterial cytochromes. Bact. Rev. 18, 106.

SNeath, P. H. A. (1960). A study of the bacterial genus Chromobacterium. Iowa St. J. Sci. 34, 243.

Stevenson, J. P. (1959). A note on the genus Aeromonas. J. gen. Microbiol. 21, 366.

Türck, L. (1952). Zur Differenzierung der Bakterien der Alkaligenes-Gruppe. I. Mitteilung. Morphologie und Physiologie. Z. Hyg. InfektKr. 134, 300.

Wetmore, P. W. \& Gochenour, W. S. (1956). Comparative studies of the genus Malleomyces and selected Pseudomonas species. I. Morphological and cultural characteristics. J. Bact. 72, 79.

Winslow, C.-E. A., Kligler, I. J. \& Rothberg, W. (1919). Studies on the classification of the colon-typhoid group of bacteria with special reference to their fermentative reactions. J. Bact. 4, 429. 